\title{
Measuring the Economic Integration of Immigrants-A Cross-National Comparison Between Canada and Germany
}

\author{
Isabella Krysa and Sharmistha Nag
}

\begin{abstract}
This paper compares the economic integration of immigrants into the labor force between Germany and Canada. Both Canada and Germany rely on immigrants to remain competitive in the economy due to low birth rates and an aging population in both countries. Canada and Germany are based on two contradictory discourses in their consideration of immigration. While Canada has relied since its colonization by the British and French on immigrants for economic expansion and nation building, Germany never considered itself to be an immigrant country, but rather as a host of guest workers who would leave 1 day when their labor power was not needed any longer. Thus, a cross-national comparison between two opposing immigration discourses is a valuable contribution to the global research on immigration as it can highlight similarities and differences in the successful economic integration of immigrants. Further, it can point to determining factors that contribute to the economic integration of immigrants. In order to measure if the two countries have differences in the success of economic integration of immigrants, the measures of unemployment rates, field of work, and income of immigrants are compared and contrasted.
\end{abstract}

Keywords Integration of immigrants $\bullet$ Comparative analysis $\bullet$ Economic success of immigrants

\footnotetext{
I. Krysa $(\triangle)$

Management Department, Fairleigh Dickinson University, Vancouver, BC, Canada

e-mail: i.krysa@fdu.edu

S. Nag

Department of Economics, Fairleigh Dickinson University, Vancouver, BC, Canada
} 